\title{
RESEARCH AND CURRICULA DEVELOPMENT AT NORWEGIAN UNIVERSITIES
}

From the early years to the mid-1970s

Terje O. Espelid, Arne Maus, Svein Nordbotten, Knut Skog, Arne Sølvberg

1. Espelid, University of Bergen, Dept. Informatics ,HIB - Thormøhlensgt. 55, N-5020

Bergen; terje@ii.uib.no

2. Maus, University of Oslo, Dept. Informatics, P.O.Box 1080|N-0316 Blindern, Oslo,

Norway; arnem@ifi.uio.no

3. Nordbotten, Professor Emeritus, University of Bergen, Dept. Information Science;

Svein.Nordbotten@infomedia.uib.no

4. Skog, Professor Emeritus, NORUT Information Technologies, Science Park Tromsø;

Knut.Skog@itek.norut.no

5 .Sølvberg, The Norwegian University of Science and Technology (NTNU), Dept. Computer and Information Science, Sem Scelands v. 7, N-7491 Trondheim, Norway;

Arne.Soelvberg@idi.ntnu.no

Abstract: Early computing curricula in Norway were based on training courses in programming that were developed as computers were made available for research at universities and research institutes during the 1950's. These developed into formal curricula starting from the mid-1960s. This developed differently at the different universities, which account for in the sequel. It describes the main points in the development of research profile and curricula for the four Norwegian universities.

Key words: Norwegian universities, history, curriculum, research

\section{INTRODUCTION}

All four Norwegian universities introduced formal computer curricula during the period 1963-73. They started differently at the four universities and developed different research profiles. A common feature was heavy 
emphasis on software, software engineering and on computer applications. The universities are in Bergen, Oslo, Trondheim, and Tromsø. The University of Oslo is the oldest of the four, and is a classical university, which at the time had approximately 15-20.000 students. The University of Bergen is also of a classical profile but had considerably fewer students, approximately 5-7000. The University of Trondheim was a loose federation of two professional schools, one technical university (NTH - Norges Tekniske Høgskole) with approximately 3000 students, and one school of a more classical profile, which had grown out of a teachers' seminar, and had a similar number of students. They just established the world's most northern University of Tromsø and had only few students and a young, enthusiastic academic staff. From 1960 to 1975, the Norwegian universities increased their student numbers by 10.000 every fifth year, from 10.000 in 1960 to 40.000 in 1975 . During this considerable expansion, it was possible to absorb a very rapid building up also of Computer Science education.

At the University of Oslo, the first professor was Ole Johan Dahl. In 1968 he moved to the University from the Norwegian Computing Center (Norsk Regnesentral) were he had been inventing the first object oriented programming language Simula together with Kristen Nygaard. For this, they shared the John von Neumann medal in 2002 and the A. M. Turing award in 2001. Dahl joined the numerical mathematics group of the University's Department of Mathematics, and after ten years his group in computer science and the numerical analysis group together with the cybernetics section of the Department of Physics, formed in 1977 a separate Department of Informatics at the University of Oslo. Dahl's work on programming and compiler technology was very influential in forming the scientific profile of the curriculum, and on teaching of computer science as a whole in Norway. Programming, programming languages, non-numerical algorithms but also several courses in numerical methods was at the core of the curriculum.

In Bergen, the Faculty of Natural Sciences and Mathematics organized the first curriculum with emphasis on numerical analysis and programming in 1963. Kjell J. Overholt of the Department of Mathematics was primus motor and a master degree in applied mathematics with specialty in numerical analysis and programming was established in 1964 . Both the research and the curriculum reflect a strong mathematical influence in the first decade. Today the Department of Informatics has six strong research groups with emphasis on theoretical computer science. The Faculty of Social Sciences organized its' first curriculum in 1972 which placed heavy emphasis on computer applications. The first professor was Svein Nordbotten who moved to Bergen from the Norwegian Bureau of Census, where he had been responsible for the Bureau's computer operations. He established a scientific profile of Information Systems at the new Department of Information Sciences. The Norwegian Business School is 
also situated in Bergen, and organized a separate line of Information System specializations in the mid-70's, with Professor Leif Methlie, who later developed research and teaching in expert systems, financial systems and recently in e-commerce.

In Trondheim, there were several parallel developments at NTH (the technical university). They organized a University Computing Center in 1962 and immediately started to teach large number of students in programming. Research and teaching grew up during the 1960s at the departments of Engineering Cybernetics (Professors Balchen, Pettersen and Landsverk), Telecommunication (Professor Sørbye), and Industrial Engineering (Professor Bjørke), where computer courses were offered during the last year of engineering studies. Other important application departments were Structural Engineering (Professor Holand), Ship Design (Professor Moe) and Chemical Engineering (Professors Borgen and Cyvin). In 1967, the first distinct computer science education of one year and a half became an elective at the study of Technical Physics. In 1972, this resulted in the establishment of a Department of Data Processing at the Faculty of Mathematics, Physics, and Economics, which took over the teaching obligations of the University Computing Center, and some of its staff such as Professor Arne Sølvberg who became the first department chair. The computing center heritage formed the research profile and the teaching profile in Trondheim largely, with heavy emphasis on computer applications in general, and in software engineering.

In 1972, the first students enrolled at the northernmost university in the world, the University of Tromsø. A geophysical research laboratory in Tromsø already existed in 1928 for the study of Aurora Borealis, atmospheric electricity, terrestrial magnetism, and allied phenomena. This activity became the starting point of the Department of Physics at the university, and included a dedicated computing laboratory. The laboratory had the responsibility of providing computer services to the entire new university and allocated seven scientific positions. This organized mixture of computer services and science was based on experience from medicine where on the job training was and still is a fundamental aspect of education and research. In 1973, Knut Skog, who had been instrumental in setting up the Computing Center in Trondheim, became professor at Tromse's computer laboratory. After two years of internal debate, the laboratory and a Department of Computer Science separated into two separate departments. Skog had spent time in 1962 with Peter Naur's group at Regnecentralen in Copenhagen when a GIER computer with its Algol compiler arrived at NTNU as its first computer. His interest for computer applications and computer operations from his Computer Center years in Trondheim blended with his expertise in programming languages and influenced the Tromsø curriculum to have heavy emphasis on software engineering. 
Therefore, we see that the roots were different for computer research and education at the four universities. Trondheim and Tromsø had a heavy influence by an engineering culture that came out of NTH - the Norwegian Technical University. In Oslo, the early co-habitation of computing and mathematics influenced the research profile into a more theoretical strand. In Bergen, the activity remained organizationally divided, and refined their respective research profiles to a more application-oriented strand at the Faculty of Social Sciences, and a profile of theoretical computer science at the Department of Informatics. The sequel that follows gives a more detailed account of the historic development at the four universities.

\section{THE UNIVERSITY OF BERGEN}

At the University of Bergen the first computer, an IBM 650 (nicknamed Emma), were installed at the Department of Geophysics in April 1958. This was the result of an initiative by Professor Carl L. Godske and a consortium, EMMA A/S (acronym for Elektronisk Matematikk MAskin), consisting of the university and private companies in the Bergen region were behind the investment. The plan was to use Emma both for commercial and scientific tasks. This marks the start of both the Computing Center and the use of computers in science at the University of Bergen. Emma soon became out of date and was followed in the first decade by IBM 1620 I (1962/63), IBM 1620 II (1964) and IBM 360/50H (1967) with Kåre Floysand as the head of the Computing Center, [UIB96]. Godske's scientific interests were in meteorology, climate, and hydrodynamic models. They illustrated the fact that in the initial period, the computers' ability to do number crunching was the focus. It was therefore quite natural that the Department of Mathematics in 1963 offered the first two Computer science courses for students: one in numerical analysis and one in programming. In 1964, a new graduate program (cand. real.) in applied mathematics with particular emphasis on numerical analysis and programming was established with Kjell J. Overholt as primus motor.

\subsection{Informatics at Bergen's Faculty of Natural Sciences and Mathematics}

In the spring of 1963, university lecturer Kjell J. Overholt at the Department of Mathematics gave the first formal course in numerical analysis ( 5 credits out of 10 credits totally per semester) for approximately ten students. A student laboratory based on electromechanical calculators (twelve machines) was available to help students do the practical 
computations. In the autumn 1963, Professor Ernst S. Selmer, Department of Mathematics, and Kåre Fløysand, The Computing Center, gave the first programming course (5 credits) for approximately ten students, [UIB96]. Three different programming languages were taught: an assembly language and Bell's interpretative language (Emma) and FORTRAN (IBM $1620 \mathrm{I}$ ). The students got practical programming experience through exercises in searching, sorting, number theory, and numerical methods (the spring course was a prerequisite). Both teachers and students gathered around the computers once a week in order to run their punched cards programs giving a 'hands on experience' and creating a strong feeling among the students of being part of a pioneer era.

In 1964, the Department of Mathematics established a new master degree within applied mathematics with emphasis on numerical analysis and programming and in the autumn of 1966, the first group of four students graduated with this specialty. Overholt consulted Carl Erik Frøberg, the first editor of BIT, who gave advice concerning which topics to include in this education. Among the topics were Algol, numerical linear algebra and numerical solution of differential equations.

The 60-ties represents a pioneering time for education in 'informatikk', a term inspired by French and coined as the Norwegian name of a field including 'numerisk analyse' and 'databehandling' in the last half of the seventies. The number of students studying the introductory programming course steadily increased and counted 120-150 in the early seventies. In the exercises, the focus on numerical methods was weakened and emphasis on other application areas of computers strengthened. The curriculum for undergraduate studies were restructured and in 1973, ten years after the start, these students were offered three different courses in 'databehandling', 9 credits totally, including one course in data-structures in addition to an introductory programming course and a course focusing on assembly languages and computer architectures. The Department of mathematics had at this time, 1969, bought its' first computer, NORD-1, and this was used both in teaching and for master projects.

Introducing a new master degree, cand. scient., in Norway in 1979 implied a total revision of the curriculum and 'informatikk' appeared for the first time independent of the curriculum in mathematics in Bergen. The curriculum contained 40 credits of informatics subjects offering both themes relevant in other fields in science as well as complete master studies in 'Informatikk'. The number of students exploded in the early 1980 s with the result that access both to the introductory programming course (maximum 260 ) and the master program became regulated.

The 1960s was a golden age for the Norwegian universities and at the Faculty of Natural Sciences and Mathematics in Bergen, they used this to strengthen the activities in mathematics, chemistry and physics recruiting 
new faculty members. In 1968 , the first position dedicated to this new field was advertised and Kjell J. Overholt was appointed as the first docent in this field. By 1973 the faculty had increased to three members and ten years later, 1 January 1984, they established the Department of Informatics by moving the informatics group from the Department of Mathematics and the group counted at that time six faculty members. The Faculty of Natural Sciences and Mathematics developed a plan in 1983 [IIPlan83] for strengthening of the field Informatics and in the next ten-year period, the staff grew from six to fourteen members. In this period the Department expanded the curriculum especially on the master level and in addition established a formal research education through a Dr. scient. program, [IIUIB97].

Today the Department of Informatics has 24 faculty members divided into six research groups that varied in size from three to five members. These groups were in algorithms, bioinformatics, coding theory and cryptography, numerical analysis, optimization, and finally a programming technology group. Bioinformatics is an activity dating back to 1992, while the other five themes goes back at least twenty years, numerical analysis, algorithms and optimization being the oldest. The department has a theoretical orientation and in a recent international evaluation of ICT in Norway initiated by the Norwegian Research Council, all groups received a very good grade, [ICT02].

A natural question to ask today is: Why did the department establish these particular research fields? Looking back at the first twenty years or so the staff constantly had a high teaching burden taking into account both undergraduate and graduates. In this phase the group preferred open jobdescriptions while announcing vacancies, rather than to restrict the research area to a specific field. This way one was able to attract well-qualified applicants. At some point it was time for consolidation: in order to create strong research groups vacancies were used to strengthen the ongoing activities rather than to spread a small staff too thinly on the enormous informatics field, [IIUIB97].

\subsection{Information Science at Bergen's Faculty of Arts}

In the humanities and social sciences, some disciplines started early to use computers in their research. In the natural sciences, extensive and complex computations were dominating, while in humanities and social sciences the organization, storage, processing, and retrieval of large numerical and textual data sets became the more important tasks.

The pioneers outside the natural sciences were Professors Stein Rokkan and Ludvig Holm-Olsen at the Faculty of Arts who about 1965 started work 
on the idea of developing an academic training for researchers in social sciences and humanities to use modern computer equipment in their research. In 1970, their initiative resulted in funding for one professor and two associate professors in the discipline, which they named informasjonsvitenskap (information science). They appointed a professor from the beginning of 1972 and shortly after the appointed two associate professors. The following year, the informasjonsvitenskap organized as a separate department, Institutt for informasjonsvitenskap, in the newly established Faculty of Social Sciences, with responsibilities for serving both the Faculty of Arts and the Faculty of Social Sciences.

The course structure was four sets of courses with a four-level progression, each level corresponding to a semester. The four areas were system theory and development, program tools and programming, data organization, storage and retrieval, and hardware related topics. After the two years of coursework, the students had the possibility of preparing a dissertation corresponding to three semester's full-time work. This course structure has remained with a few modifications for about 25 years. Exams from informasjonsvitenskap were accepted, with exams from other disciplines, as components in the degrees Cand.mag., Cand.philol, Cand.polit. and to a more limit extent, in the degrees Cand. real. and Cand.scient., as well as in degrees from Norges Handelshøyskole.

From half a dozen students starting in 1972, the number of students at the department grew rapidly. Candidates with degrees in information science were well received in public administration and private industry. The number of students exploded in the early 1980 s with the result that they had to regulate access to the department.

Research at the Institutt for informasjonsvitenskap was from the first years focused on problems and tasks in large computer based information systems and the organization of large data sets associated with such systems. When work on administrative information systems started at $\mathrm{NHH}$, their group became a close cooperation partner.

On the national arena, Institutt for informasjonsvitenskap, was one of the founders in 1976 of the original Norsk Informatikkradd in which the department found other partners at other universities and schools. Within the other Nordic countries, many contacts happened among which the impulses received from Professors Børje Langefors and Peter Naur were particularly important. 


\section{THE UNIVERSITY OF OSLO}

The use of electronic computers at the University of Oslo predates any organized teaching by many years. The first computer (Nusse, 1954) was a homemade version built at the Physics Department by the new Center of Industrial Research (SI) after a British model, APEXC. They soon moved that computer from the university campus. The first computer for general use by researchers and administrative staff was the Wegamatic 1000 (1960), followed by an IBM 1620-I (1962) and IBM 1620 -II (1964). It was not until the CDC 3300(1967-76) with its multitasking operating system made it practical to have a large number of students running their exercises mixed with much heavier physicists or chemist calculations and the payroll and other administrative tasks by the university administration. The infrastructure was then ready for teaching computer courses, as we now know them [Jacobsen01, NR02]. We must note that teaching of computer courses and the running of the computer itself was for many years (19641972) organized in the same administrative unit - at the numerical analysis section of the department of mathematics.

Typical for that early period was the fascination by the computer itself. One saw the establishment of national computer centers ("every country should have one") - in Norway in 1952. Later, central computers appeared at various research organizations including every university and in every bank and major public administrative organization. The purchase of any publicly owned computer or computer equipment became a strategic decision in Norway that required approval by the State Council for Data Processing.

Typical for the 1960s was then a short user courses in how to program, operate, and run your own program on a specific computer. At and around the University of Oslo, the preferred programming language was Algol 60. Several short courses were available in the early 1960s, especially at the NR - the Norwegian Computing Center.

\subsection{The 1970 curriculum at the University of Oslo}

Even though the Department of Physics had courses in cybernetics and electronics, they did not develop a full computer related curriculum. That task was the responsibility given to the section for numerical analysis of the Department of Mathematics. From the first recorded courses, we find one pure computer course using Algol 60 in 1964 called "Introduction to programming of electronic computers" and a numerical analysis course entitled, "Analysis and execution of calculating tasks on electronic computers". Later on in 1969, that last course expanded into two courses, 
"Numerical Analysis I" and "Numerical Analysis II". In 1969, courses had also started at the Department of Physics where we find "Information theory I", "Signal statistics", "Regulation technology" and "Computer technology". Until 1970, we find, however, no coherent curriculum.

In 1968 Ole Johan Dahl, one of the two inventors of Simula (the first object oriented programming language), was appointed professor at the Department of Mathematics in numerical analyses (that professorship was almost ten years later converted to one in computer science). He very soon designed three courses at the undergraduate level in addition to a number of graduate courses. The first undergraduate course titled "Non-numerical methods" - which is the all-familiar course in "algorithms and data structures" - also some years later writing a very good textbook for that course together with Dag Belsnes [DahlBelsnes73]. The title of the course drew some wry remarks from a fellow professor at the Department of Mathematics that it was strange for their first full professor in numerical analysis to entitle his course on "Non-numerical methods". Dahl also designed undergraduate courses in "Machine language and operating systems" and "Programming languages". The entire undergraduate curriculum from 1970 [Jonassen74] on was then (with percentage of a semesters work in parenthesis) as follows.

DB0 - Basic course in the use of computers. (with FORTRAN) (20\%)

DB1 - Numerical Methods I. (50\%)

DB2 - Machine language and operating systems. $(30 \%)$

DB3 - Non-numerical methods (algorithms and data structures).(40\%)

DB4 - File-systems (administrative systems) (30\%)

DB10 - Programming languages (grammars and compilation) $(30 \%)$

DB1 1 - Automata theory. (30\%)

DB20 - Numerical Methods II. (40\%)

DB21 - Numerical solutions of partial differential equations. (40\%)

DB30 - Mathematical optimization. (60\%)

This curriculum was then permanent for almost six years, when the numerical section of the Department of Mathematics became the Department of Informatics in 1977 by also joining with the section for cybernetics at the Physics Department. The Faculty of Mathematical and Natural Sciences dictated the use of FORTRAN in the beginners course DB0. However, after some years this changed to a more substantial course using Simula (50\% of a semester). If one should characterize this curriculum, one could use the two terms "Computer Science" and "Numerical Analysis". 


\subsection{A note on early curriculum related research at the University of Oslo}

One might think that the inventors of object orientation, Ole-Johan Dahl and Kristen Nygaard would continue their research in that direction, but only partly so. First, the term "object-orientation" did not yet exist and secondly, they thought Simula was only one among many new promising programming languages at that time. Dahl was however eager to demonstrate to his students the ability of the class concept to model lists, trees and graphs. He also organized graduate courses in discrete simulation using Simula. However, only after Allen Kay had designed Smalltalk (heavily influenced by Simula) did the term "object-orientation" appear. Ole-Johan Dahl, after having successfully assisted the implementation on Simula on the CDC 33000, and introduced Simula into his courses, went on to formal specification and verification of programs, which he by and large continued with for the rest of his life. The proof system Abel and the book "Verifiable programming" are here the main results. Kristen Nygaard designed two new languages, Delta for the specification of systems (not machine compilable) and Beta, intended to be a more well structured, clean, orthogonal, object oriented language. In addition, Nygaard started the systems development group at the department where he, among other aspects, introduced the workers right to participate in systems design. The early work of the numerical section of the department, headed by Tom Lyche, made them well known for their work on splines (the Oslo algorithm) and for their continued work on partial differential equations.

\section{THE NORWEGIAN UNIVERSITY OF SCIENCE AND TECHNOLOGY}

The University of Trondheim went through a major reorganization in 1995 and changed its name to Norges Teknisk-Naturvitenskapelige Universitet (NTNU) - the Norwegian University of Science and Technology. Another reorganization in 2001 led to a formation of the departments of computer and information sciences, telematics, telecommunications, electronics, engineering cybernetics and mathematics into one new Faculty of Information Technology, Mathematics, and Electrical Engineering. All of the basic computer science and telecommunication disciplines were by this organized under one leadership. The faculty is of considerable size. Approximately $400 \mathrm{MSc}$ 's and $30 \mathrm{PhD}$ 's in ICT received education in 2002 and a substantial number of students who major in other subjects receive supportive IT-education. The road to this 
situation has been long and bumpy. The sequel covers the first years of the travel towards the current organizational harmony.

NTH - The Technical University of Norway - was rather late in introducing computers in research and teaching. When they completed it on a broad scale starting in 1963, the pace forward was remarkable. In a couple of years, the number of students in introductory courses went from zero to a thousand. By 1964, almost every department of NTH had substantial research activities that needed computers, and introductory courses in computer programming became a common part of the education of most engineering students.

At the department of Engineering Cybernetics, Jens Glad Balchen (now Professor Emeritus) initiated in 1952 the construction of the electronic differential analyzer DIANA. Digital control elements appeared around 1955. Applications initiated for numerical control in industrial engineering in cooperation with Norwegian industry and the Department of Industrial Engineering at NTH. Digital computer capacity for research and development came from others, mostly from the Norwegian Defense Research Institute at Kjeller who had the then large FREDERIC computer.

\section{1 “Out-sourcing" to SINTEF: The service bureau approach}

By 1958 , it became clear for the NTH leadership that the university had to find better solutions for satisfying both the scientific needs for computing power, and the needs of the university administration. The Rector had a meeting with IBM during the autumn of 1959 , but decided to delay the starting of internal proceedings until they filled the vacant professorship in numerical mathematics. NTH's "Computer Committee" appeared in early 1961 and recommended the alternatives of buying either an IBM 7074 or a GIER computer from Regnecentralen in Denmark. Indications from the Government were that there would be no room for the more expensive IBM solution in NTH's next budgets. NTH's response was to develop the GIER solution.

While everybody agreed on the need for a digital computer, it was difficult to find good solutions within the university organization for operating the computer, and for establishing a solid economic base for future expansions. The chosen solution was an early form of "outsourcing". In 1950 NTH had been instrumental in establishing the contract research organization SINTEF, which in cooperation with NTH conducted externally funded research. SINTEF had the organizational flexibility needed for the task. They negotiated an arrangement between the two during 1961, and in 
February 1962 , NTH formally asked SINTEF to take the responsibility for operating a computing center at NTH.

The main idea was that NTH should provide computers and office space, while SINTEF provided staff. SINTEF paid all computer services and SINTEF would have some free computer capacity, and be permitted sell this to industry, in order to use the income to pay for staff and additional equipment. A new organizational unit, Regnesenteret NTH, became a SINTEF department during the autumn of 1962. The young research assistant Knut Skog had been in Denmark over the winter working on the GIER computer, and became the temporary leader for the effort until they found a permanent manager. The arrangement was very successful. The essential elements of the chosen organizational structure lasted for more than twenty years until a major reorganization took place in 1984 .

This "outsourcing" arrangement had deep and lasting consequences for computer science teaching and research at NTH. Not only did they outsource the computer operations, but they outsourced teaching to SINTEF as well, until they established a university Department of Data Processing ten years later. Implicit in the organizational arrangement was that they should finance operations by income from selling computer power and associated services in the NTH-external market. NTH had in effect created a service bureau to provide for its computer needs. Education of future users soon became an important priority for Regnesenteret, in order to be able to sell more computer power and services. Students and university staff provided the central customer group. The training courses developed during the first years provided the kernel of later curricula. The service bureau background of the first curricula has had a lasting effect on choosing priorities and directions of computer science teaching at NTNU until this day.

The first manager of Regnesenteret NTH was Norman Sanders. He came late 1962 from Boeing's Computing Center, and set up shop in a very short time. By 1965, the staff had expanded to 25 persons. There were four groups for computer operations, administrative data processing, technical computing, and education. SINTEF's contract research profile influenced the priorities of research and development that they did. The attitude was pragmatic and oriented towards application of computers. Theoretical computer science had meager conditions. Norman Sanders returned to Boeing in 1965 and Nils Høeg, who also came from Boeing's computing operations, succeeded him. Karl Georg Schjetne took over as leader of Regnesenteret in 1971 and stayed on well into the 1980s.

Regnesenteret NTH became involved in a number of development projects. Some of them led to systems that have lived on until this day, for 30-40 years, the original system solutions surviving scores of modifications, and the many major changes in computer technology of the last 30 years. 
Examples are SAPO (development started 1966 by Bjørn Nagel), which is SINTEF's project management system, and BIBSYS (development started 1970 by Ingeborg Torvik Sølvberg), which is the Norwegian national library automation system for research- and university libraries. A third example is a class scheduling system for schools (development started in 1964, Harald Michaelsen), which is still in use. Another example is UNINETT (development started 1976), which originally was a data net for Norwegian universities and research institutes but which later on has become an even more central part of the Norwegian data net infrastructure. We can trace the roots of UNINETT to 1964 when Regnesentret started to experiment with remote computing over the telephone net.

During the first year of operation of Regnesentret more than one thousand students and staff were given introductory courses in programming. Over the next few years, the introductory programming course found it way into the curricula of the various engineering studies. In 1967 , around 750 students took the course as part of their normal studies. NTH admitted 730 new students that year. After only five years since the arrival of the first computer at $\mathrm{NTH}$, almost all of the engineering students had a mandatory introductory course in programming.

NTH had a heavy bias towards Algol from the start. The GIER computer, which arrived to NTH in November 1962, was an Algol computer. Peter Naur's GIER Algol compiler was the second realization of Algol 60, a couple of months the junior of Dijkstra's compiler. Because of the high quality of its software, GIER was a remarkably attractive computer, in spite of its modest hardware capabilities. When the UNIVAC 1107 replaced the GIER in 1965 as the major "work-horse", FORTRAN emerged as a major contender to Algol. Even if UNIVAC had an Algol compiler, the language gradually gave way to FORTRAN, COBOL, Simula, and Pascal. Nevertheless, the Algol roots of NTNU's teaching are still easily spotted.

\subsection{Computer science became part of the academic structure at NTH in 1972}

In 1968 , the education group at Regnesentret gave eight different courses for a total of 1400 students, which expanded to $12-15$ courses and 2500 students at the end of the decade. There were some additional courses at the Electrical Engineering departments, particularly at Engineering Cybernetics and the Telecommunication department, and several user-oriented courses were available elsewhere, but for limited numbers of students. The teaching volume at Regnesenteret was outgrowing the "outsourcing" arrangement. It was time to organize computer education as an academic discipline. 
There was a beginning discussion about whether NTH should organize specialist education in computer science. There were two opposing views. One view was that we should teach programming as support subjects in existing engineering curricula. According to this view, computing was not a "real" discipline that could stand by itself, but was a support discipline in a similar role as mathematics. Specialization in computing should occur in the context of studies of "real" disciplines, like physics, mathematics, and electrical engineering. The other view was that the future would see the emerging of a large information technology sector that had its own knowledge needs, and that specialist education at the universities had to support this emerging sector.

The support discipline view won the first battles. One-year specialization curricula occurred in physics and in electrical engineering. It soon turned out that each specialization comprised the same basic computer courses in, for example, in programming and databases. NTH's teaching tradition was to organize specialized departments to teach courses of common interest to many of the other disciplines, e.g., the mathematics department teaches all of the common mathematics courses for the engineering students. Therefore, they decided to establish a Department of Data Processing, and place this together with other "service teaching" departments like mathematics and economics. It is well worth noting the choice of name for the new department. While other universities chose names like informatics, computer science, and information science, NTH chose the mundane name of "data processing" for its new academic discipline. This choice reflects the service bureau roots of the computer education of NTNU. The Norwegian name was "Institutt for Databehandling", abbreviated to IDB, in the best of the three-letter abbreviation tradition of the computer industry.

As a concession to the "specialist education" view, they decided to give the new department a quota for an intake of twenty students a year to a master track in "data processing" of $2 \frac{1}{2}$ years. This started in 1972. The computer science track in physics became the new "data processing" track, but continued at electrical engineering. The Department of Engineering Cybernetics hired Olav Landsverk as their computer engineering professor who offered specialization in computer architecture, and also offered a realtime computer system specialization with Odd Pettersen. The Department of Telecommunication likewise continued to offer education in digital technique for telecommunication systems with Professor Håkon Sørbye and colleagues.

The first of a series of university reorganizations took place in 1970 when the University of Trondheim (UNIT) established with NTH as a major part. Regnesentret NTH expanded its activities to all parts of the university and changed name to Regnesentret ved Universitetet $i$ Trondheim, or RUNIT for short. There were intentions of having IDB to serve all parts of 
the UNIT, but organizational structure of the new university could not easily accommodate this, and IDB served NTH first, and rest of the University on an ad hoc basis. All of the courses were open for all of UNIT's students, but only NTH offered organized curricula in computing.

The "data processing" IDB-department grew out of the education group at Regnesentret. Key persons who have been with IDB from the start are Kjell Bratbergsengen, Reidar Conradi, Arne Halaas, and Arne Sølvberg, who where youngsters at the time, and still are active professors at the department. By more recent student generations, they were known as "the gang of four". Olav B. Brusdal, who had been with Regnesentret from the start after spending time in Copenhagen where he participated in building NTH's GIER computer, joined IDB in 1975, and stayed until he retired in 2000. Tore Amble was in the original group, but went elsewhere for many years until he returned to the department in 1990 .

There were three possible specializations in the master track program in "data processing", in programming, in information systems, and in numerical mathematics. There was no requirement of prerequisite computer courses except of the introductory course in programming. The first year of the $2 \frac{1}{2}$-year master track in data processing consequently had to be filled with elementary computer science material. This became less than desirable by IDB's scientific staff, and a potential danger for the students' chances to compete effectively in the job market. Therefore, IDB started a lobbying campaign for persuading the university leadership of the need for a full $4 \frac{1}{2}$ year curriculum in data processing. The campaign succeeded. The first students for a full 41/2 -year engineering study started in 1978 .

The major point in the new arrangement was that students could apply directly for a full $4 \frac{1}{2}$-year master study in data processing on equal footing with electrical engineering, industrial engineering, and all of the others. The intake was only twenty students a year. The number of applicants was overwhelming. The young ones had already sensed that change was in the air, and that the IT-age was emerging. The intellectual quality of the student intake was amazing. The curriculum changed by moving courses that are more elementary to the first two years. The low number of students did not permit a wider specialization than in the original three tracks. They retained the "data processing" attitude to the teaching of the subject. Emphasis on project-oriented teaching was heavy. Industry well received the resulting knowledge profile of the students. Our students became very attractive in the job market.

In 1962 computer technology was unknown territory at NTH, except for a very few. It took fifteen years to reach full recognition for the new discipline at NTH, through the decision in 1977 to establish a full engineering curriculum, on equal footing with the already established engineering disciplines. 


\subsection{Continuous reorganizations and growth has led to NTNU's Faculty of Information Technology, Mathematics and Electrical Engineering}

The characterization for the next 25 years included frequent reorganizations and steady growth in students and staff. The student increases have always come prior to staff increases. The teaching load has consequently always been high. This has been the case almost everywhere in our discipline, and we are no exception.

In most cases, reorganizations have reflected changes in the technology. During the late $1970 \mathrm{~s}$, it became quite clear that the telecommunication industry was changing its technological basis from electronics to software. In 1983, this perceived development led to the merging of IDB, the Telematics group of the Telecommunication Department, and the Computer Architecture group of Engineering Cybernetics. The new department changed name to the "Institutt for Datateknikk og Telematikk", abbreviated to IDT, and moved to the Electrical Engineering Department, which in the process, changed its name to Electrical Engineering and Data Technique, abbreviated to ED!! The reorganization coincided with a major expansion of the IT education in Norway, which took place between 1986 and 1990. The number of computer science majors doubled and NTH took the lion's share. The new IDT department consequently got a flying start. It is always easier to reorganize during expansion than during contraction!!

IDB was always engineering oriented. The non-engineering part of the University of Trondheim decided to establish its own Department of Information Science (IFI - Institutt for Informasjonsvitenskap) in the beginning of the 1980's. The scientific profile was somewhat "softer" than IDB's, in particular after IDB became IDT. During the major reorganization of the University of Trondheim in 1995 the IDT-department, which had been formed only 10 years earlier, was broken up. The Telematics-part of IDI formed a new department at Electrical Engineering, while the old IDB together with Computer Architecture was moved to a new Faculty for Physics, Informatics and Mathematics, and in this process merged with IFI. The new department got was named "Institutt for Dateknikk og Informasjonsvitenskap", abbreviated to IDI. Once more, the reorganization coincided with a major expansion of computer science education in Norway, of which NTNU again got the lion's share. The new faculty lasted only for 6 years, when IDI and the Mathematics department in 2002 merged with electrical engineering to form the current Faculty of Information Technology, Mathematics, and Electrical Engineering.

A long and bumpy road it has been. Who says that universities can't change??? 


\section{THE UNIVERSITY OF TROMSØ}

The computing environment got a flying start by being attractive as an exiting location for young pioneering scientists from the University of Oslo and by attracting 8-10 graduate students mostly from the northern part of the country, having their undergraduate background from both Oslo and Bergen. During a very short time, we were a group of 15 to 20 people trying to form a research profile of our own. In particular, the rapidly growing capacities of the "processors on a chip" and the microcomputer (the earliest PC) caught the attention of this young faculty from the very beginning.

An attempt to turn the department into a graduate school did not receive approval. The teaching burden of the undergraduate curriculum in addition to the teaching of some 20 graduate students was growing fare above the young department's most flexible limits. The department was the youngest and smallest of the four departments of the Faculty of Mathematical and Physical Sciences. As a result, it was constantly in the minority when the voting for more lecturing capacity had taken place. Bridging the gap between demand and supply of teaching capacity obviously took time that otherwise should be spent on research.

\section{REFERENCES}

[DahlBelsnes73] - Ole-Johan Dahl og Dag Belsnes: Algoritmer og datastrukturer. Studentlitteratur, Lund 1973

[ICT02]-Research in Information and Communication Technology in Norwegian Universities and Colleges, A Review, NFR 2002.

[IIPlan83]- Plan for utbygging av Informatikk-faget, Det matematisk-naturvitenskaplige fakultet, UiB, 1983.

[IIUiB97]- Oppsummering av perioden 1984-1996 og langtidsplaner, Institutt for informatikk, $\mathrm{UiB}, 1997$.

[Jonassen 74] - Arne Jonassen: Gjøkungen, databehandling og numerisk analyse,

Mat. inst. avd. D, Univ. i Oslo 1974.

[Noodt97] - Aud Veen Noodt: :Datahistorien ved Universitetet $i$ Oslo, Institutt for informatikk 1977-1997,

Inst for Informatikk, 1997.

[Jacobsen01] - Per H. Jacobsen: IT-historien@UiO, USIT 2001

[NR02] - Lars Holden og Håvard Hegna: Norsk Regnesentral 1952 - 2002, NR, 2002

[UIB96]- Nils Roll-Hansen et al.: Universitetet i Bergens historie, Bind II, UiB, 1996. 